\title{
In honor of Professor Klaus G. Heumann
}

\author{
Alfredo Sanz-Medel ${ }^{1}$ • Jörg Bettmer ${ }^{1}$
}

Published online: 15 August 2016

(C) Springer-Verlag Berlin Heidelberg 2016

All founding editors of Analytical and Bioanalytical Chemistry (ABC), the new journal started almost 15 years ago, should be acknowledged for their dedication, professionalism and efforts to nurture that baby journal born in 2002 .

The decisive contribution of those eminent analytical and bioanalytical scientists was essential to explain the outstanding development of $\mathrm{ABC}$ from its inception to its steady growth in the following decade to compete with so many rival, already well-established, analytical journals.

In this general context, the personal contribution of former editor Prof. Klaus Heumann has been particularly relevant and valued. Klaus has been one of those admired colleagues who always listened carefully to others before finally giving his own opinion, his particular vision and insights to the problem at hand: an informed opinion full of logic and wisdom to illuminate our discussions.

Alfredo Sanz-Medel: Believe me Klaus, your thorough way of thinking and sound discourse will be missed in our future meetings of the renewed scientific board. Thank you for your efforts, friendship and "savoir-faire" as one of the internationally recognised scientists and former editors of $\mathrm{ABC}$, who pushed hard to put Analytical and Bionalytical Chemistry at the forefront of bioanalytical research scientific journals worldwide (Fig. 1).

Professor Dr.-Ing. Klaus Gustav Heumann was Professor of Analytical Chemistry at the Johannes Gutenberg-University of Mainz, Germany, until his retirement in 2005. He received his $\mathrm{PhD}$ from the Technical University of Darmstadt under the

Alfredo Sanz-Medel

asm@uniovi.es

1 Department of Physical and Analytical Chemistry, University of Oviedo, C/ Julián Clavería 8, 33006 Oviedo, Spain supervision of Professor Karl Heinz Lieser in 1969, followed by his habilitation in 1974. In the same year, he accepted a professorship at the University of Regensburg, where he stayed until he moved to the University of Mainz in 1996.

His scientific achievements have significantly contributed to the development of modern analytical chemistry, either methodologically or in applications. Amongst others, the development of negative thermal ionisation mass spectrometry (NTIMS) for a number of metals and non-metals using isotope dilution analysis; precise and accurate isotope ratio measurements (e.g. Os isotope ratio measurements for the application of the Re-Os dating method in geology); the development of on-line isotope dilution analysis (species-unspecific or post-column isotope dilution analysis) in hyphenated techniques; and studies on the transformation, transfer and transport of elemental species in the southern hemisphere have been his outstanding contributions to the scientific community. Unsurprisingly, these achievements were awarded several prizes, such as the "Océ van der Grinten Award for Environmental Analytical Chemistry 1987",

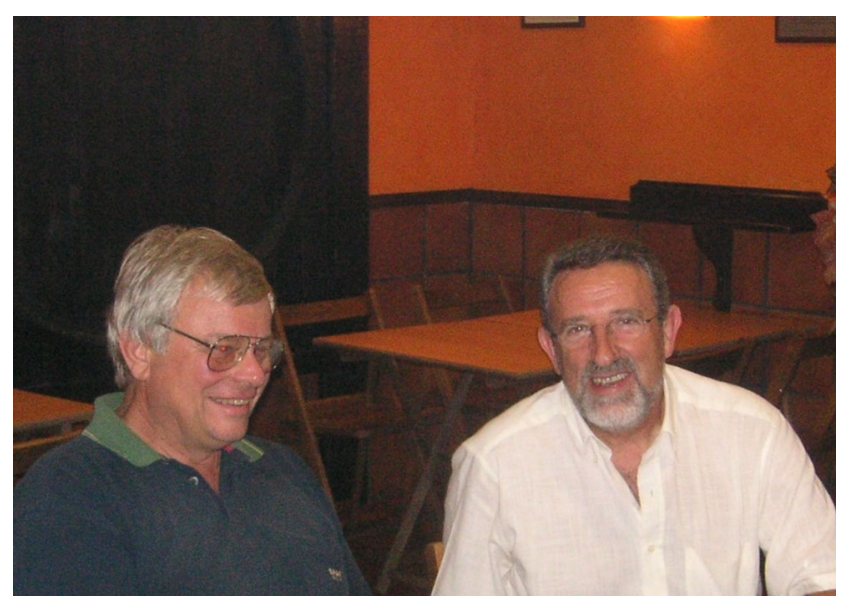

Fig. 1 Klaus Heumann and Alfredo Sanz-Medel in Oviedo 2005 


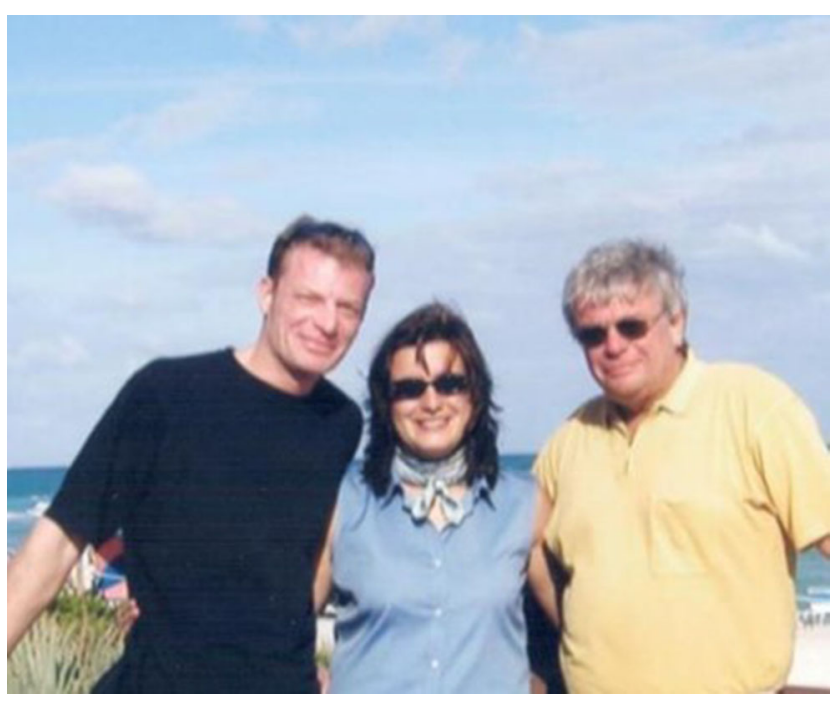

Fig. 2 Jörg Bettmer, Maria Montes-Bayón and Klaus Heumann during the "Winter Conference on Plasma Spectrochemistry 2004" in Fort Lauderdale

the "Clemens-Winkler-Medal 2005" and the "European Award for Plasma Spectrochemistry 2007”. In 2013, he became Honorary Member of the German Working Group of Applied Spectroscopy (DASp; now merged with A.M.S.El. to DAASGerman Working Group of Analytical Spectroscopy). What is probably more important for him is that he can look back on the graduation of about $70 \mathrm{PhD}$ and master students during his time at the University of Regensburg and the University of Mainz; many of them still active in the analytical chemistry community, in either academia or industry. Every year, he organises an alumni meeting to bring together his "scientific family".

During his career, Klaus G. Heumann was very active in various organisations and committees. He was board member of the Analytical Chemistry Section of the GDCh (German
Chemical Society), member and president of the DGMS (German Society of Mass Spectrometry), secretary and chairman of the IUPAC Commission on Atomic Weights and Isotopic Abundances, to name just a few distinguished functions. $\mathrm{He}$ initiated the "Symposium on Mass Spectrometric Techniques for Trace Element Analysis" in 1987, nowadays the most important German/Swiss/Austrian meeting on elemental mass spectrometry, and established an annual forum for German university professors of Analytical Chemistry. There have been many more activities worth mentioning, but surely a personal (and also institutional) highlight was the initialisation of the graduate programme "Trace Analysis of Elemental Species: Method Development and Applications" funded by the DFG (German Research Council) and the federal state Rhineland-Palatinate from 2002 to 2011. At that time, it was the only graduate programme on analytical chemistry in Germany and allowed the instruction of about $50 \mathrm{PhD}$ students in an interdisciplinary environment. This was only possible thanks to his dedication and personal engagement. During this time, he primarily took care of students and their adequate instruction, and not necessarily of the peculiarities of his colleagues.

Jörg Bettmer: Klaus, as one of your former co-workers, I would stress here how your devoted promotion of young scientists, as a university lecturer or scientific and personal mentor, have benefited many analytical colleagues of the "younger generation". Besides your continuous support and personal advice, your analytical way of thinking and critical assessment of situations were of utmost influence for me, and I am very grateful that I have had the privilege to learn directly from you during time at the University of Mainz and thereafter (Figs. 2 and 3).

For sure, a personal highlight to remember was the joint organisation of the "European Winter Conference on Plasma
Fig. 3 Klaus Heumann (left) with part of his research group during an excursion in 2004 (Jörg Bettmer, $3^{\text {rd }}$ from the right)

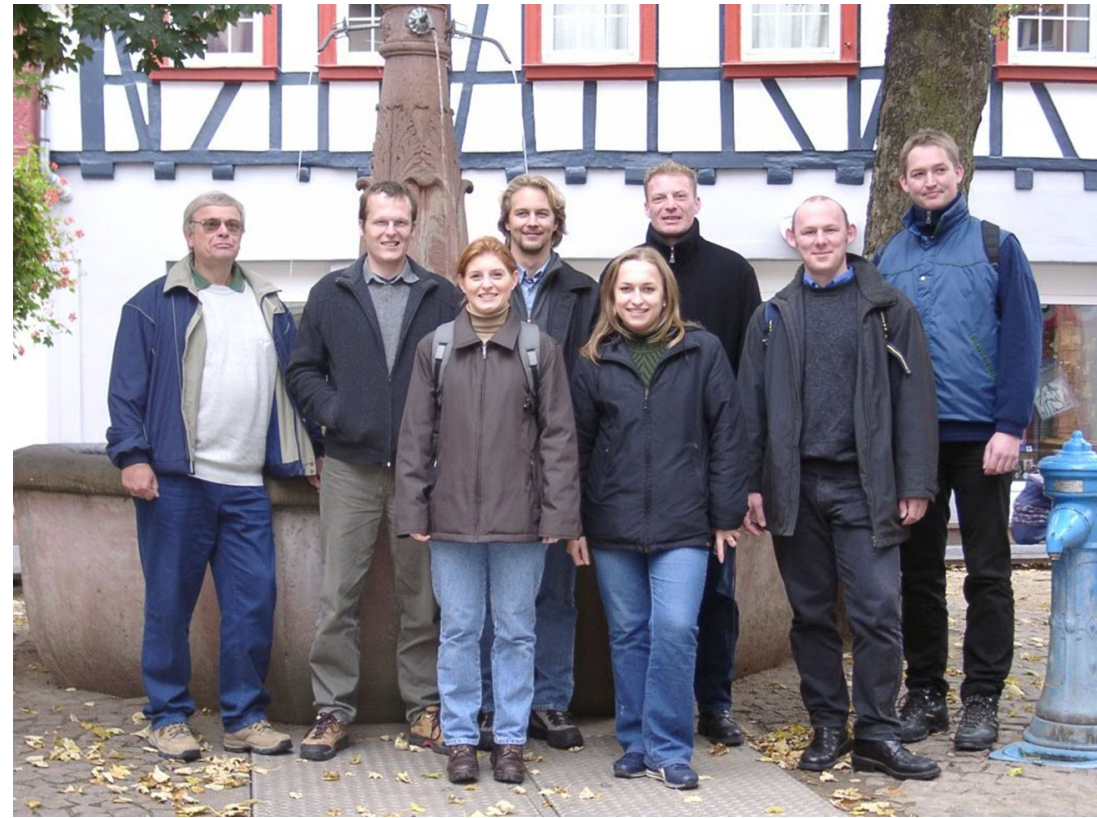


Spectrochemistry 2003" in Garmisch-Partenkirchen. It was a great success in many aspects! Besides being the chairman of the meeting, you also acted, probably unintentionally, as my personal "Cupid" and paved the way for an exciting relationship and marriage, for which I am also grateful to you every day. Amongst other reasons, it has resulted in a long-range scientific collaboration and personal friendship between Oviedo, Mainz and Zwingenberg.
Dear Klaus, we wish that health accompanies you as you continue with your manifold leisure activities: cycling, playing golf, travelling with Martina to the most beautiful places in the world, entertaining your grandchild, just enjoying life. You always stressed that wherever you travel you will have some friends. Be sure that you are always welcome to visit your friends in Oviedo.

Jörg and Alfredo 